\title{
Familial Amyloid Polyneuropathy: Receptor for Advanced Glycation End Products-Dependent Triggering of Neuronal Inflammatory and Apoptotic Pathways
}

\author{
Mónica Mendes Sousa,, ${ }^{1}$ Shi Du Yan, ${ }^{2}$ Rui Fernandes, ${ }^{1}$ António Guimarães, ${ }^{3}$ David Stern, ${ }^{2}$ and \\ Maria João Saraiva ${ }^{1,4}$ \\ 1/nstitute for Cellular and Molecular Biology, ${ }^{2}$ Departments of Pathology, Surgery, and Physiology and Cellular Biophysics, \\ Columbia University, New York, New York 10032, 3Hospital Geral de Santo António, Porto 4150-180, Portugal, and \\ 4/nstituto de Ciências Biomédicas Abel Salazar, Porto 4099-003, Portugal
}

Familial amyloid polyneuropathy (FAP) is a neurodegenerative disorder associated with extracellular deposition of mutant transthyretin (TTR) amyloid fibrils, particularly in the peripheral nervous system. We have hypothesized that binding of TTR fibrils to the receptor for advanced glycation end products (RAGE) on critical cellular targets is associated with a destructive stress response underlying peripheral nerve dysfunction. Analysis of nerve biopsy samples from patients with FAP $(n=$ 16) at different stages of disease (0-3), compared with agematched controls $(n=4)$, by semiquantitative immunohistology and in situ hybridization showed increased levels of RAGE, beginning at the earliest stages of the disease (FAP 0; $p<0.02$ ) and especially localized in axons. Upregulation of proinflammatory cytokines (tumor necrosis factor- $\alpha$ and interleukin-1 $\beta$ ) (approximately threefold; $p<0.02$ ) and the inducible form of nitric oxide synthase (iNOS) $(\sim 2.5$-fold; $p<0.04)$ was also observed in a distribution overlapping RAGE expression. Tyrosine nitra- tion and increased activated caspase- 3 in axons from FAP patients $(p<0.03)$ were apparent. Although these data suggest the presence of ongoing neuronal stress, there was no upregulation of neurotrophins (nerve growth factor and neurotrophin-3) in FAP nerves. Studies on cultured neuronallike, Schwann, and endothelial cells incubated with TTR fibrils displayed RAGE-dependent expression of cytokines and iNOS at early times ( 6 and $12 \mathrm{hr}$, respectively), followed by later ( $24 \mathrm{hr}$ ) activation of caspase-3 and DNA fragmentation. We propose that the interaction of TTR fibrils with RAGE may contribute to cellular stress and toxicity in FAP. Furthermore, there is an apparent lack of responsiveness of Schwann cells in FAP nerve to provide neurotrophic factors.

Key words: familial amyloidotic polyneuropathy; amyloid; transthyretin; RAGE; caspase-3; inducible nitric oxide synthase; inflammatory cytokine
Familial amyloid polyneuropathy (FAP) is a neurodegenerative disorder characterized by the extracellular deposition of amyloid fibrils composed of mutant forms of transthyretin (TTR) in several tissues, particularly the peripheral nervous system (Coimbra and Andrade, 1971a,b). Among the point mutations in TTR promoting amyloidogenesis (Saraiva, 2001), the most common is a substitution of Val for Met at position 30 (V30M) (Saraiva et al., 1983). TTR amyloid deposits are distributed diffusely in the peripheral nervous system, involving nerve trunks, plexuses, and sensory and autonomic ganglia (Coimbra and Andrade, 1971b). Amyloid deposits in peripheral nerves occur especially in the endoneurium, where they appear close to Schwann cells (SCs) and collagen fibrils (Coimbra and Andrade, 1971a). In severely affected nerves, endoneurial contents are replaced by amyloid, and few nerve fibers retain viability. By contrast, the CNS in FAP is relatively spared, except for the ependymal lining and lepto-

\footnotetext{
Received May 9, 2001; revised July 18, 2001; accepted July 19, 2001.

This work was supported by grants from PRAXIS XXI (35785/99 and 35735/99), Portugal, from the United States Public Health Service (AG17490, AG16223), and from the Surgical Research Fund. M.M.S. is the recipient of a postdoctoral fellowship (PRAXIS XXI/BPD/22027/99), and R.F. is the recipient of a BTI Fellowship (PRAXIS XXI/BTI/PL021902) from Fundação para a Ciência e Tecnologia, Portugal. We thank Paul Moreira for the production and purification of recombinant TTR.

Correspondence should be addressed to Maria João Saraiva, IBMC-Amyloid Unit, R. Campo Alegre, 823, 4150-180 Porto, Portugal. E-mail: mjsaraiv@ibmc.up.pt. Copyright (C) 2001 Society for Neuroscience $\quad 0270-6474 / 01 / 217576-11 \$ 15.00 / 0$
}

meninges. Outside the nervous system, extensive amyloid deposits have been observed throughout connective tissue in a perivascular distribution.

The accumulation of extracellular, crossed $\beta$-sheet fibrils is a hallmark of amyloidoses. Pathologically, fibrillar accumulation appears to be closely linked to dysfunction of the surrounding cells and vasculature. This view of FAP pathogenesis would suggest that nerve fiber degeneration results from multifocal compression by amyloid deposits (Said et al., 1984). However, unmyelinated fibers (UFs) that are primarily affected in FAP are more resistant to compression than myelinated fibers (MFs). Similarly, despite the presence of vascular amyloid, evidence of compromised blood flow sufficient to adversely affect organ function has not been demonstrated in FAP (Fujimura et al., 1991).

Local cellular activation, ultimately resulting in cell dysfunction and death, may contribute to the pathogenesis of amyloidrelated disorders. In Alzheimer's disease (AD), the close association between expression of inflammatory mediators (cytokines, chemokines, complement proteins, acute phase reactants), activated astrocytes and microglia, and neuritic plaques has suggested a prominent role for immune/inflammatory pathways in the neurodegenerative process (Mrak et al., 1995; Smith et al., 1997; Veerhuis et al., 1999). Among the candidate mechanisms through which pathogenic forms of amyloidogenic molecules might perturb cellular properties is engagement of cellular receptors. The receptor for advanced glycation end products (RAGE) displays 
increased expression in FAP tissues and has been shown to bind fibrillar TTR triggering nuclear factor (NF)- $\kappa \mathrm{B}$ expression (Sousa et al., 2000). The possible involvement of RAGE in the biology of amyloidoses was strengthened by the recent demonstration that RAGE bound amyloid A, and that blockade of RAGE suppressed splenic expression of proinflammatory cytokines, NF- $\kappa$ B activation, and accumulation of amyloid in a model of systemic amyloidosis (Yan et al., 2000). RAGE is a member of the immunoglobulin superfamily with a broad repertoire of ligands in addition to amyloid-associated macromolecules, including products of nonenzymatic glycoxidation (advanced glycation end products), proinflammatory mediators (S100/calgranulins), and amphoterin (Hori et al., 1995; Yan et al., 1996, 1999, 2000; Hofmann et al., 1999). In each case, the receptor recruits signal transduction mechanisms, often resulting in a sustained and pathogenic inflammatory response (Yan et al., 1996; Schmidt et al., 1999; Hofmann et al., 2001).

In the present work we initiated a systematic evaluation of the relationship between RAGE and FAP, on the basis of the hypothesis that expression of the receptor in FAP tissue at early times might contribute to the pathogenesis of evolving cellular dysfunction.

\section{MATERIALS AND METHODS}

FAP patients. Sural nerve biopsy specimens from FAP patients $(n=16)$ and normal controls $(n=4$; near-relatives of FAP patients who ultimately turned out not to have mutations in TTR) were available in the Hospital Geral de Santo Antonio (Porto, Portugal), because this material was obtained as part of the clinical diagnosis and evaluation of polyneuropathy in this region of Portugal, before the current use of less invasive methods. Initial characterization of clinical material included morphometric studies of nerve fiber density and abundance of amyloid deposits. Patients were scanned for mutations in TTR by immunoblotting (Saraiva et al., 1985). The general characterization of the patients under study is shown in Table 1.

Morphometric studies were performed on sural nerve biopsy tissue fixed in glutaraldehyde $(2.5 \%)$ in $0.1 \mathrm{M}$ cacodylate buffer, $\mathrm{pH} 7.4$, postfixed in osmium tetroxide, and embedded in Epon. Quantitation of myelinated fibers in semithin sections was performed in an area of at least $0.1 \mathrm{~mm}^{2}$ at a magnification of $1000 \times$. Myelinated fibers were counted, their diameters were measured, and the density was calculated. Unmyelinated fibers were counted from thin sections in an area of at least $0.005 \mathrm{~mm}^{2}$, and their densities were calculated. A scoring system of patient material was based on morphometry of MFs and UFs: FAP 0 $(n=5)$, no reduction in the number of fibers (MFs $\sim 10,000$ fibers $/ \mathrm{mm}^{2}$; UFs $\sim 50,000$ fibers $/ \mathrm{mm}^{2}$ ); FAP $1(n=4)$, discrete reduction (MFs varied between 7000 and 2000 fibers $/ \mathrm{mm}^{2}$; UFs varied between 4000 and 40,000 fibers $/ \mathrm{mm}^{2}$ ); FAP $2(n=4)$, evident reduction (MFs $\sim 1000$ fibers $/ \mathrm{mm}^{2}$; UFs $<10,000$ fibers $\left./ \mathrm{mm}^{2}\right)$; and FAP $3(n=3)$, severe reduction (MFs $<1000$ fibers $/ \mathrm{mm}^{2}$; UFs absent). Standard values for control nerves ranged from 7000 to 11,000 fibers $/ \mathrm{mm}^{2}$ for MFs and from 30,000 to 80,000 fibers $/ \mathrm{mm}^{2}$ for UFs (see Table 1).

Amyloid deposition was assessed by Congo red staining and in most cases was inversely proportional to nerve fiber density (Coimbra and Andrade, 1971b). In FAP 0 patients, amyloid was absent (by Congo red staining), but immunohistochemical reaction of TTR was detected. A semiquantitative index of amyloid deposition in endoneurium and epineurium included the following: 0 , no amyloid; 1 , scarce amyloid deposition; 2, several amyloid deposits; and 3, abundant amyloid. All histologic measurements were made independently by two pathologists unaware of the patient's clinical diagnosis. The presence of Congo red-positive areas was closely correlated with immunoreactivity with TTR.

Immunohistochemistry. For immunohistochemical analysis, paraffin sections were deparaffinated, dehydrated in a modified alcohol series, and incubated in blocking buffer [1\% bovine serum albumin (BSA) and $4 \%$ horse serum] for $30 \mathrm{~min}$ at $37^{\circ} \mathrm{C}$ in a moist chamber. Incubation with primary antibody, at the appropriate dilution in blocking buffer, was performed overnight at $4^{\circ} \mathrm{C}$. Primary antibodies were rabbit polyclonal
anti-TTR IgG (Dako, Glostrup, Denmark; 1:300), murine monoclonal anti-human RAGE (1:25), polyclonal rabbit anti-RAGE IgG (Yan et al., 2000) (1:300), goat anti-human interleukin (IL)-1 $\beta \operatorname{IgG}$ and goat antihuman tumor necrosis factor (TNF)- $\alpha$ IgG (Santa Cruz Biotechnology, Santa Cruz, CA; 1:25), rabbit anti- inducible form of nitric oxide synthase (iNOS) IgG (Chemicon, Temecula, CA; 1:2500), rabbit anti-endothelial NOS (eNOS) IgG (Chemicon; 1:100), rabbit anti-neuronal NOS (nNOS) IgG (Chemicon; 1:1000), rabbit anti-3-nitrotyrosine IgG (Chemicon; $1: 1000)$, rabbit anti-activated caspase-3 IgG (PharMingen, San Diego, CA; 1:25), monoclonal anti-human CD68 $\operatorname{IgG}_{1 \mathrm{k}}$ (Dako; 1:10), monoclonal anti-human CD11b, Mac1 IgG1 (Chemicon; 1:10), monoclonal antimyelin basic protein $\mathrm{IgG}_{1}$ (Chemicon; 1:300), rabbit anti-factor V III IgG (Sigma, St. Louis, MO; 1:200), monoclonal anti-smooth muscle $\alpha$-actin $\mathrm{IgG}_{2 \mathrm{a}}$ (Sigma; 1:100), rabbit anti-neurofilament $200 \mathrm{IgG}$ (Sigma; 1:200), rabbit anti-brain-derived neurotrophic factor (BDNF) IgG (Chemicon; $1: 1000)$, sheep anti-nerve growth factor- $\beta$ (NGF $\beta$ ) (Chemicon; 1:500), and rabbit anti-neurotrophin $3 \mathrm{IgG}$ (NT3) (Chemicon; 1:1000). Antigen visualization was performed with either biotin-extravidin-alkaline phosphatase or biotin-extravidin-peroxidase kits (Sigma), using Fast Red (Sigma) or 3-amino-9-ethyl carbazole (Sigma), respectively, as substrates. On parallel control sections, primary antibody was replaced by blocking buffer. Double staining was accomplished by decolorizing the first stain with $95 \%$ ethanol and blocking peroxidase activity with hydrogen peroxide (3\%)/methanol for 15 min. Subsequent immunohistochemistry was performed with either affinity-purified alkaline phosphatase- or peroxidase-conjugated secondary antibody (Sigma). Semiquantitative analysis of immunohistochemical images was performed with the Universal Imaging system (NIH). The results shown represent percentage $( \pm \mathrm{SD})$ of the image area occupied by a particular immunoreactivity.

In situ hybridization. Digoxigenin-labeled probes were transcribed from the plasmid B379-2A (Brett et al., 1993) containing a 1406 bp fragment of bovine RAGE and PCRII containing a $470 \mathrm{bp}$ fragment of mouse IL-1 $\beta$ (a kind gift of Dr Shi Fang Yan, Columbia University, New York), using the DIG RNA labeling kit (Roche, Indianapolis, IN). Antisense probe for RAGE was transcribed from the T3 promoter with the plasmid linearized with $X h o I$, and control sense probe was transcribed from the T7 promoter with the plasmid linearized with $X b a$ I. Antisense probe for IL-1 $\beta$ was transcribed from the T7 promoter with the plasmid linearized with SpeI, and a control sense probe was transcribed from the SP6 promoter with the plasmid linearized with XhoI. The digoxigeninlabeled RNA probes were hybridized to cellular mRNA by standard procedures and detected with anti-digoxigenin alkaline phosphataseconjugated antibody. Antibody was visualized with X-phosphate and nitroblue tetrazolium salt.

Proteins. Human soluble RAGE (sRAGE) was expressed using the baculovirus system and purified to homogeneity (Yan et al., 1996). Recombinant TTR was purified from Escherichia coli BL21 transformed with plasmids carrying wild-type TTR cDNA as described (Almeida et al., 1997). TTR fibrils were generated from soluble wild-type TTR (2 $\mathrm{mg} / \mathrm{ml}$ ) by incubation with $0.05 \mathrm{M}$ sodium acetate, $\mathrm{pH} \mathrm{3.6,} \mathrm{for} 48 \mathrm{hr}$ at room temperature (Bonifacio et al., 1996). Formation of amyloid fibrils was tested by thioflavin T fluorescence. The lipopolysaccharide (LPS) content of protein preparations was tested using the Limulus amebocyte assay (Sigma). At a protein concentration of $2 \mathrm{mg} / \mathrm{ml}$, sRAGE had no detectable LPS. Similarly, TTR at a concentration of $1 \mathrm{mg} / \mathrm{ml}$ was free of LPS.

Cell lines and cell culture. RN22 (rat Schwann cell line), PC12 (rat adrenal cell line with a neuronal-like phenotype), and BAE-1 (bovine aortic endothelium cell line) were from the European Collection of Cell Cultures. Wild-type mouse embryonic fibroblasts (MEF1s) were kindly provided by Dr. Miguel Seabra (Imperial College, London). All cell lines were propagated in $10 \mathrm{~cm}$ dishes in monolayers and maintained at $37^{\circ} \mathrm{C}$ in a humidified atmosphere of $95 \%$ and $5 \% \mathrm{CO}_{2}$. Cells were grown in DMEM (Life Technologies, Gaithersburg, MD) supplemented with $10 \%$ fetal bovine serum (FBS) (Life Technologies) and $100 \mathrm{U} / \mathrm{ml}$ penicillin (Life Technologies) (complete media). Primary cultures from dorsal root ganglion (DRG) were prepared from $\sim 250$ DRGs from neonatal to 3 -week-old mice. DRGs were suspended in DMEM containing 10\% collagenase/dispase stock solution (Sigma) and incubated at $37^{\circ} \mathrm{C}$ for 1 hr. After dissociation of the tissue, the suspension was centrifuged at $1000 \mathrm{rpm}$ for $10 \mathrm{~min}$, and the resulting pellet was washed with DMEM three times to remove excess collagenase. For primary SCs, cells were resuspended in $10 \mathrm{ml}$ per $\sim 20$ DRGs in DMEM supplemented with $0.1 \%$ BSA, 20\% FBS, $30 \mathrm{~mm}$ glucose, and $2 \mathrm{~mm}$ glutamine and plated in $10 \mathrm{~cm}$ 
dishes (10 ml per dish) coated with laminin (Sigma) and incubated for 2.5 hr at $37^{\circ} \mathrm{C}$. During this period, nearly all non-neuronal cells attach, leaving neurons in the culture supernatant. Cell culture media was aspirated and replaced by fresh media. SCs were grown to a confluent monolayer over $\sim 7 \mathrm{~d}$. To obtain neuron DRG, cells were plated in Matrigel (Sigma) in neuronal growth media: DMEM supplemented with $100 \mathrm{ng} / \mathrm{ml}$ nerve growth factor (Life Technologies), 5\% FBS, and 1\% B27 supplement (Life Technologies). The purity of primary cultures used for experiments was $>85 \%$ neurons and $>80 \%$ SCs, based on staining with antibody to neurofilament 200 and myelin basic protein in neuronal and Schwann cell cultures, respectively.

For RT-PCR and caspase-3 assays, cultured cells were grown in complete media in six-well dishes. For cell death detection, cells were grown in 96-well plates. When $\sim 80 \%$ confluence was reached, cells were washed with HBSS and incubated with assay buffer (DMEM containing 1\% dialyzed FBS) with the indicated amount of either soluble or fibrillar TTR for the time periods shown for each experiment. For studies using specific antibodies, nonimmune (NI) IgG or sRAGE, cells were preincubated for $3 \mathrm{hr}$ with the indicated amount of antibody, NI IgG, or protein $(10 \mu \mathrm{g} / \mathrm{ml}$, unless stated otherwise $)$.

$R N A$ extraction and RT-PCR. Total RNA extraction was performed using Trizol reagent (Life Technologies) according to the manufacturer's instructions. The concentration of total RNA was determined spectrophotometrically in RNase-free water. Reverse transcription was performed using $10 \mu \mathrm{g}$ total RNA and Superscript II (Life Technologies), primed by oligo-dT following the manufacturer's instructions. PCR $\left(94^{\circ} \mathrm{C}\right.$, $3 \mathrm{~min}, 1 \mathrm{cycle} ; 94^{\circ} \mathrm{C}, 20 \mathrm{sec}, 56^{\circ} \mathrm{C}, 45 \mathrm{sec}, 72^{\circ} \mathrm{C}, 1 \mathrm{~min}, 30$ cycles; $72^{\circ} \mathrm{C}, 6 \mathrm{~min}$, 1 cycle) was performed using $1 / 10$ of the obtained cDNA. The following primers were used: for IL-1 $\beta$, sense (5'-ATGGCAACTGTTCCTGAACTCAACT-3') and antisense (5'-CAGGACAGG TATAGATTCTTTCCTTT- $\left.3^{\prime}\right)$; for mouse and rat TNF- $\alpha$, sense $\left(5^{\prime}\right.$-TTCTGT CTACTGAACTTCGGGGTGATCGGTCC-3') and antisense (5'-GTATGAGA TAGCAAATCGGCTGACGGTGTGGG-3'); for bovine TNF- $\alpha$, sense (5'-TTCTGTCTACTGAACTTCGGGGTGATTGGTCC-3') and antisense (5'-GTATGAAATGGCAAACCGGCTGACGGTGTGGG-3'); for mouse and rat iNOS, sense (5'-GGAACCTACCAGCTCACTCTG-3') and antisense (5'-CCACTTC AGCCCGAGCTCCTG-3'); for bovine RAGE, sense (5'-AGCGGCTGGAATGGAAA CTGAACA-3') and antisense (5'-GAAGGGGCAAGGGCACA CCATC-3'); for mouse and rat RAGE, sense (5'-ATGGCAGCAGCGTGTCGGAGC-3') and antisense (5'-GGGACCCTTAGCTGGCACTTAGAT-3'); for BDNF, sense (5' CGGCCCAACG AAGAAAACC-3') and antisense (5'-TAAGGGCCCGAACATACGATTGG-3'); for NGF, sense (5'-GGCCCATGGTACAATCCCTTTCA-3') and antisense (5'-TCA GCCTCTTCTTGTAGCCTTCCT-3'); and for NT3, sense (5'-AGCCGATTGCA ACAGACAC-3') and antisense (5'-CCAGCGCCAGCCTACGAGT-3'). To normalize and control differences in total RNA concentration among samples, mRNA levels for $\beta$-actin were determined by RT-PCR using the following primers for mouse and rat $\beta$-actin: sense (5'-GTGGGCCGCTCTAGGCACCAA$\left.3^{\prime}\right)$ and antisense (5'-CTCTTTGATGTC ACGCACGATTTC-3'); and for bovine $\beta$-actin, sense (5'-CTATCCCTGT ACGCCTCTGGC-3') and antisense (5'-GGCGTAGAGGTC TTTGCGGATG-3'). All PCR products were visualized in $1 \%$ agarose gels by ethidium bromide staining.

Caspase-3 assays. Activation of caspase-3 was measured using the CaspACE fluorometric 96-well-plate assay system (Promega, Madison, WI) following the manufacturer's instructions. Briefly, $80 \%$ confluent cells were exposed for $24 \mathrm{hr}$ to $1 \mu \mathrm{M}$ TTR (either soluble or fibrils) in the presence or absence of $\alpha$ RAGE or NI IgG. Subsequently each well was trypsinized, and the cell pellet was lysed in $100 \mu$ l hypotonic lysis buffer (Promega) by four cycles of freeze/thawing. Forty microliters of each cell lysate were used in duplicates for determination of caspase-3 activation. The remaining cell lysate was used to measure total cellular protein concentration with the Bio-Rad protein assay kit (Bio-Rad, Hercules, CA), using BSA as standard. Values shown are the mean of duplicates of three independent experiments.

Cell death detection. Cell death detection was performed using the cell death detection ELISAplus kit (Roche) following the manufacturer's instructions. Briefly, after incubation with $2 \mu \mathrm{M}$ TTR (either soluble or fibrils) for $24 \mathrm{hr}$, in the presence or absence of $\alpha \mathrm{RAGE}$ or N I IgG, $60 \mu \mathrm{l}$ lysis buffer (Roche) was added to each well and $40 \mu \mathrm{l}$ was used in the assay. Results presented are the mean of triplicate wells of two independent experiments.

\section{RESULTS}

\section{Increased expression of RAGE in peripheral nerve from early FAP patients}

We reported previously that FAP patients had increased expression of RAGE in affected peripheral nerves (Sousa et al., 2000). These results led us to perform a more detailed analysis of RAGE expression in FAP by analyzing sural nerve biopsies from 16 patients spanning different stages of FAP (Table 1). Patients were scored using a morphometric scale based on nerve fiber density $(0-3$, the latter representing the greatest loss of nerve fibers; see Materials and Methods). FAP 0 patients possess the V30M mutant form of TTR, normal nerve fiber density, and deposition of TTR in nerve tissue, but amyloid is not evident (i.e., immunoreactive deposits are negative by Congo red staining). It should be noted that at all other stages of FAP (1-3), immunoreactive TTR and Congo red-positive deposits were highly correlated. RAGE expression was enhanced in nerves of FAP 0 patients (Fig. 1A). Although RAGE was present in several cell types, our initial impression was that the staining pattern was most consistent with increased expression of the receptor in axons (see below). Analysis of images of five biopsies of FAP 0 patients, compared with normal age-matched controls $(n=4)$, demonstrated an approximately threefold increase in area occupied by immunoreactive RAGE in the patients (Fig. 1B) $(p<$ 0.02 ). As the course of FAP evolved, there was a tendency for RAGE expression to increase. Semiquantitative analysis showed a statistically significant difference between all stages of FAP $(0-3)$ and controls $(p<0.003)$. Although there was no statistically significant difference between FAP 1 and FAP 2 , there was a significant difference between FAP 0 and FAP 3 (Fig. $1 B)(p<$ $0.01)$.

\section{Neuronal expression of RAGE in FAP}

Because of the likely presence of RAGE in several cell types in nerve tissue from patients with FAP, a more detailed analysis to match cells expressing RAGE with those displaying markers for neurons, vascular endothelium, and Schwann cells was undertaken. Neurons showed increased RAGE staining based on colocalization with the neuron-specific marker neurofilament 200 (Fig. 1C, top panels). Vascular endothelium stained positively for RAGE and the endothelial marker Factor VIII (Fig. 1C, middle panels). It was apparent that RAGE was also present in vascular smooth muscle cells. In some cases, we found that RAGE immunoreactivity coincided with Schwann cells (Fig. 1C, bottom pan$e l s)$. Based on our survey of cells bearing RAGE antigen in FAP nerves, axons were the most abundant cellular structure displaying positive staining. Consistent with this impression, in situ hybridization using an antisense RAGE probe showed transcripts of the receptor to be predominately localized to axons of FAP nerves (Fig. 1D, top panel). Control hybridizations with either a sense RAGE probe and FAP tissue (Fig. 1D, middle panel) or an antisense RAGE probe in nerve from a control individual (Fig. $1 D$, bottom panel) resulted in only background staining.

\section{Expression of inflammatory cytokines in FAP nerve}

Previous studies demonstrated RAGE-dependent activation of NF- $\kappa$ B by TTR fibrils in vitro and nuclear staining for NF- $\kappa$ Bp50 in FAP tissues (Sousa et al., 2000). Because nuclear translocation of NF- $\kappa \mathrm{B}$ might underlie increased expression of proinflammatory cytokines, we analyzed the presence of two key mediators, IL-1 $\beta$ and TNF- $\alpha$, in affected nerves from FAP patients in relation to deposition of TTR. Semiquantitative analysis of im- 


\begin{tabular}{|c|c|c|c|c|c|}
\hline \multirow[b]{2}{*}{ FAP stage } & \multirow[b]{2}{*}{ Age (years) } & \multicolumn{2}{|c|}{ Amyloid deposition } & \multicolumn{2}{|c|}{ Fiber density (fibers $/ \mathrm{mm}^{2}$ ) } \\
\hline & & Endoneurium & Epineurium & MF & UF \\
\hline \multicolumn{6}{|l|}{ FAP 0} \\
\hline 1 & 25 & 0 & 0 & 8,700 & nd \\
\hline 2 & 17 & 0 & 0 & 7,700 & 41,500 \\
\hline 3 & 33 & 0 & 0 & 10,300 & 54,800 \\
\hline 4 & 25 & 0 & 0 & 10,800 & 57,900 \\
\hline 5 & 21 & 0 & 0 & 10,300 & 80,000 \\
\hline 6 & 25 & 0 & 0 & 7,700 & nd \\
\hline \multicolumn{6}{|l|}{ FAP 1} \\
\hline 7 & 25 & 2 & 0 & 4,360 & 41,000 \\
\hline 8 & 27 & 2 & 0 & 2,370 & nd \\
\hline 9 & 27 & 2 & 1 & 2,460 & 4,080 \\
\hline 10 & nd & 1 & 1 & 7,270 & 32,750 \\
\hline \multicolumn{6}{|l|}{ FAP 2} \\
\hline 11 & 41 & 2 & 1 & 1,620 & $<1,000$ \\
\hline 12 & nd & 1 & 0 & 1,840 & 9,600 \\
\hline 13 & 41 & 2 & 0 & 1,140 & $<1,000$ \\
\hline 14 & 58 & 2 & 1 & 1,300 & $<1,000$ \\
\hline \multicolumn{6}{|l|}{ FAP 3} \\
\hline 15 & 43 & 3 & 0 & 720 & 0 \\
\hline 16 & 41 & 3 & 1 & 0 & 0 \\
\hline 17 & 34 & 3 & 1 & 910 & 0 \\
\hline \multicolumn{6}{|l|}{ Controls } \\
\hline $18-21$ & $36-53$ & 0 & 0 & $7,000-11,000^{a}$ & $30,000-80,000^{a}$ \\
\hline
\end{tabular}

munohistochemical images for immunoreactive TNF- $\alpha$ and IL- $1 \beta$ in FAP nerve biopsies, compared with age-matched control individuals, demonstrated expression of these cytokines that coincided with the pattern observed for RAGE; namely, they were especially localized to the endoneurial axons (Fig. 2A). Although normal nerve showed virtually no detectable antigen, FAP 0 individuals (i.e., before amyloid was present) already displayed increased TNF- $\alpha$ and IL-1 $\beta$ antigens (Fig. 2A,B). Increased levels of these cytokines were also evident in FAP 1-3 individuals, in which case the pattern of TNF- $\alpha$ and IL- $1 \beta$ appeared juxtaposed to deposits of TTR. In each case, the level of cytokine appeared to increase by approximately threefold, compared with controls, and was statistically significant (Fig. $2 B)$. In situ hybridization was performed to determine the actual site of IL- $1 \beta$ mRNA synthesis. Antisense probe hybridized with FAP 1 tissue demonstrated a clear signal, consistent with axons as the principal site of IL-1 $\beta$ transcripts (Fig. $2 C$ ). In contrast, study of FAP 1 tissue with the sense IL $-1 \beta$ probe and control tissue with the antisense IL- $1 \beta$ probe displayed only background staining.

Local expression of TNF- $\alpha$ and IL- $1 \beta$ in peripheral nerve suggested the possible recruitment of leukocytes, lymphocytes, and mononuclear phagocytes to FAP lesions. However, our studies using antibodies reactive with markers on polymorphonuclear leukocytes (CD68), lymphocytes (CD11b, Mac1), and mononuclear phagocytes (F4/80) did not confirm the presence of these subpopulations of white cells. An important consideration in the interpretation of these data is that our samples were preserved in glutaraldehyde, paraffin-embedded, and stored for prolonged times. Thus, it is possible that loss of immunoreactivity could account for some of these results. However, in view of the number of antibodies tested and the absence of cellular infiltrates in FAP nerve tissue, at the level of general histologic analysis, it seems likely that there is a relative paucity of white cells in these lesions.

\section{Oxidant stress in FAP}

Oxidant stress attributable to generation of reactive oxygen and nitrogen species is likely to have an important role in neurodegenerative and neuroinflammatory disorders (Calabrese et al., 2000). High levels of NO, produced by iNOS, are known to exert multiple toxic effects on cells (Combs et al., 2001). In view of the well known link between cytokines and expression of iNOS, we probed FAP nerves for iNOS antigen. Increased levels of iNOS were observed in FAP nerves, especially in axons, in a distribution overlapping that for both RAGE and proinflammatory cytokines in FAP 0 and FAP 3 (Fig. $3 A$ ). On the basis of our semiquantitative immunohistologic evaluation of the different stages of FAP, enhanced expression of iNOS was evident in FAP 0 patients (approximately twofold) compared with controls $(p<$ 0.04 ) (Fig. $3 B$ ). Furthermore, this increase was also seen in later stages of the disease (FAP $1-3$ ), where it approached $\sim 2.5$-fold $(p<0.02)$. In contrast to these data regarding iNOS expression, no increase in immunoreactive eNOS or nNOS was observed when the same sections were analyzed (data not shown).

The reaction of NO with superoxide produces the peroxynitrite anion (Radi et al., 2001). Peroxynitrite is a powerful oxidant that can nitrate aromatic amino acid residues such as tyrosine to form 3-nitrotyrosine (3-NT). Thus, 3-NT is a useful marker of peroxynitrite production. Immunostaining of FAP nerves with antibody to 3-NT demonstrated immunoreactive material in FAP 0 
A

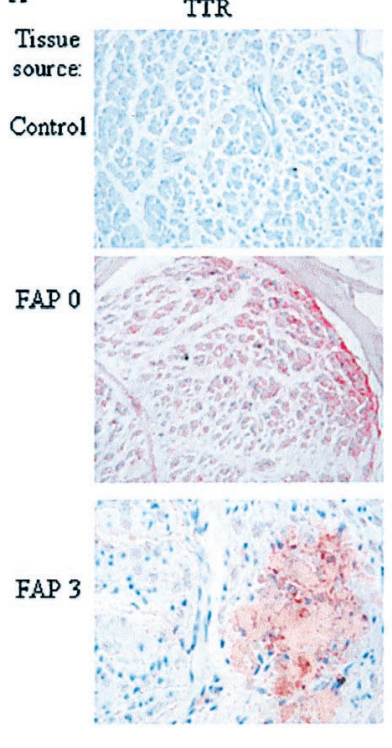

C Representative TTR (left) and RAGE (right) immunohistochemistry of nerves from normal individuals (top panel), FAP 0 patients (middle panel), and FAP 3 patients (bottom panel); 40× magnification. $B$, Quantitation of immunohistochemical images corresponding to RAGE staining in control individuals $(n=4)$ and FAP $0-3$ $(n=16)$ patients. Data are represented as percentage area occupied $\pm \mathrm{SD}\left({ }^{*} p<0.003,{ }^{\ddagger} p<\right.$ $0.02)$. $C$, Colocalization of RAGE with the neuronal marker neurofilament 200 (N200, top pan$e l$ ), an endothelial cell marker (Factor VIII, middle panel), and an SC marker, myelin basic protein $(M B P$, bottom panel); 40× magnification. Nerve tissue from a representative FAP 2 patient was used. $D$, In situ hybridization for RAGE mRNA in a representative FAP 1 nerve with an antisense riboprobe (top panel) and a control sense riboprobe (middle panel). The bottom panel shows a nerve from a control hybridized with the antisense RAGE riboprobe.
RA
RAGE

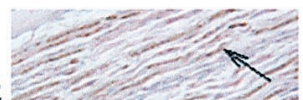

RAGE

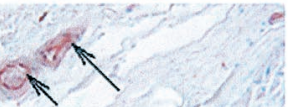

RAGE

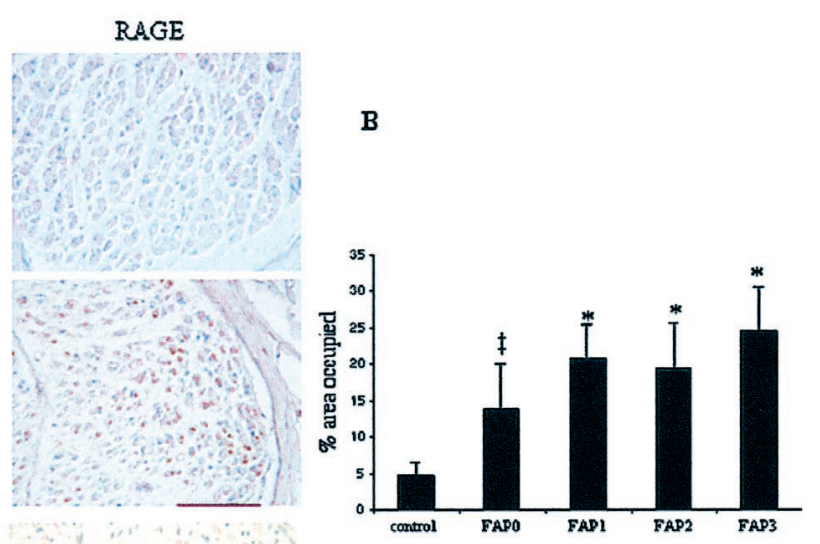

D
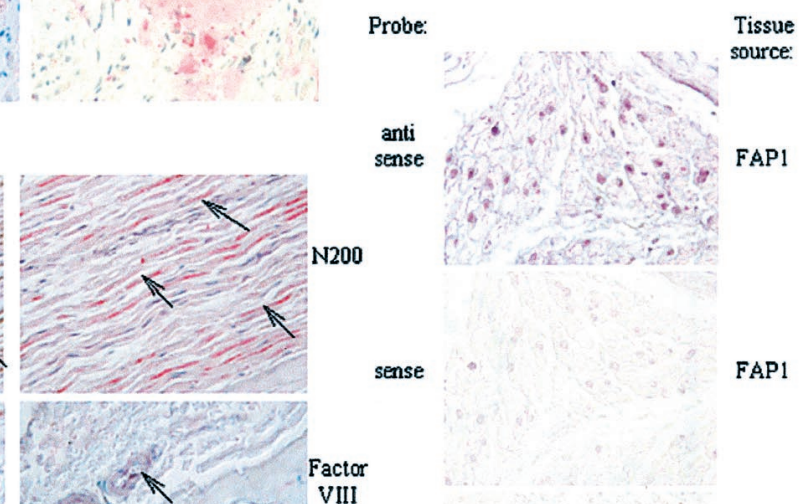

anti

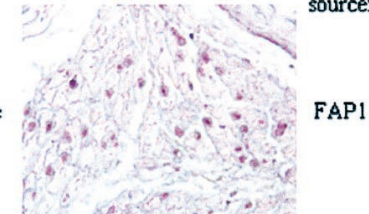

nse

FAP1

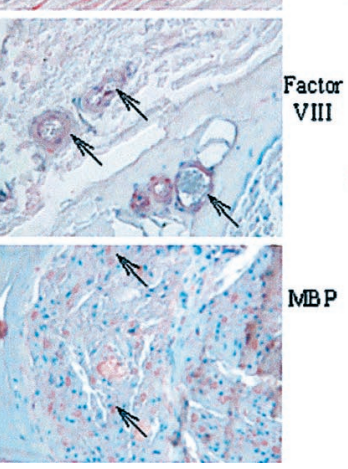

and FAP 3 tissue in an axonal distribution (Fig. $3 C$ ). The latter also showed intense staining of deposited TTR with the antibody to 3-NT, suggesting that the deposited TTR was subject to nitration (Fig 3C, right panel).

\section{Activation of an apoptotic pathway by TTR fibril-RAGE interaction}

Apoptosis is a common mechanism of cell death in neurodegenerative disorders (Hengartner, 2000). In the case of FAP, local expression of cytokines and iNOS in neurons suggested even more strongly that programmed cell death might be triggered. Apoptosis involves the activation of a proteolytic cascade where caspases have a key regulatory role (Hengartner, 2000). Caspase-3 is especially significant in this regard, because it is activated late in apoptosis. Immunostaining of FAP nerve biopsies was performed with an antibody specific for activated caspase-3. A representative micrograph of control and FAP 3 tissue demonstrates undetectable staining in the normal tissue, whereas FAP shows areas of intense staining corresponding to axons (Fig. 4A). This pattern overlapped that for expression of iNOS, inflammatory cytokines, and RAGE in FAP 3 biopsies. Comparison of results in FAP patients at each of the four stages indicated a tendency for increased activation of caspase-3, starting in FAP 0 patients but being more pronounced (fourfold; $p<$ 0.003 ) in FAP 2 and 3 (Fig. 4B) (approximately fourfold; $p<$ $0.003)$. To determine whether DNA fragmentation had occurred, TUNEL staining was attempted on the biopsy samples. However, the results could not be interpreted because of artifacts probably related to sample preparation and storage (similar results were obtained with the Apoptag kit as well).

\section{Binding of TTR fibrils to RAGE induces cell stress, ultimately resulting in cytotoxicity}

In vitro studies were performed to address whether the interaction of TTR fibrils with RAGE-bearing cells might recapitulate cell stress observed in FAP nerve biopsies. Although proinflammatory cytokines and iNOS appeared most concentrated in peripheral nerve axons, the presence of amyloid contiguous to Schwann cells and associated with the vasculature suggests the potential for interactions with these cellular elements as well. For these experiments, cell culture models were used: PC-12 cells for neuronallike cells, BAE-1 for vascular endothelium, and $\mathrm{RN}-22$ for Schwann cells, as well as primary cultures of dorsal root ganglion neurons and Schwann cells. RT-PCR analysis demonstrated ex- 
A

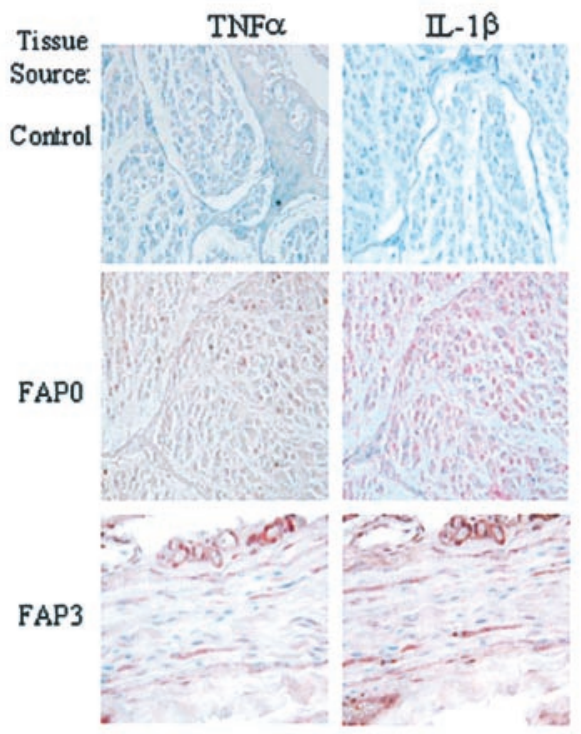

B

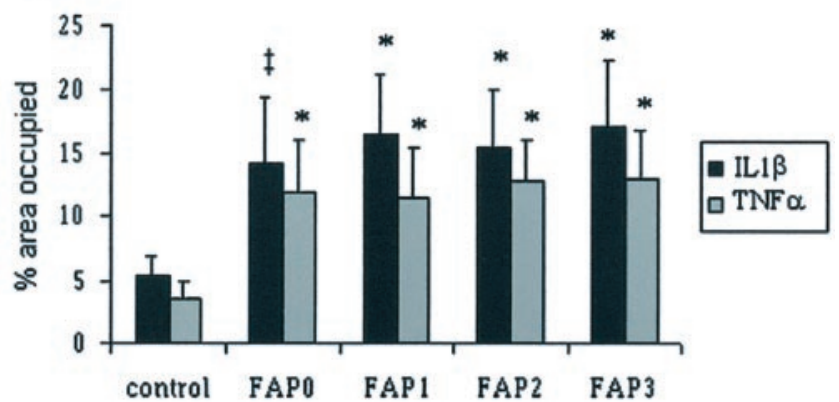

C

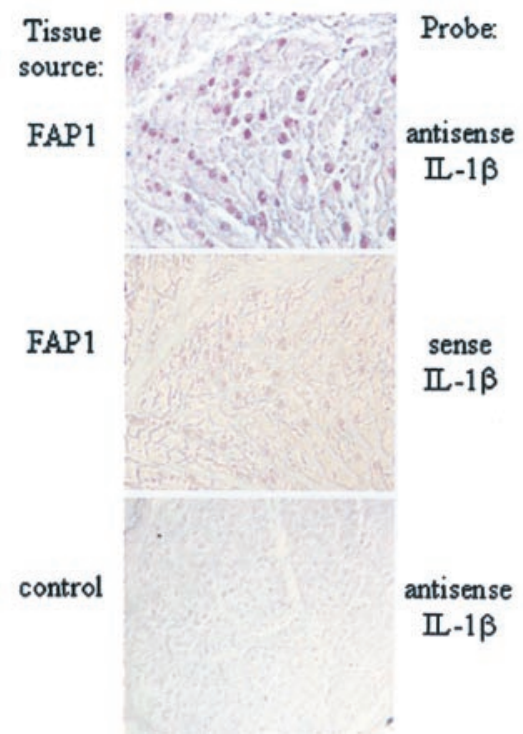

Figure 2. Expression of proinflammatory cytokines in FAP. A, Representative TNF- $\alpha$ (left) and IL-1 $\beta$ (right) immunohistochemistry of nerves from normal individuals (top panel), FAP 0 patients (middle panel), and FAP 3 patients (bottom panel); 40× magnification. $B$, Quantitation of immunohistochemical images of TNF- $\alpha$ and IL- $1 \beta$ staining in control individuals $(n=4)$ and FAP $(n=16)$ patients. Data are represented as percentage area occupied $\pm \mathrm{SD}\left({ }^{*} p<0.01,{ }^{\ddagger} p<0.02\right)$. $C$, In situ hybridization of IL- $1 \beta$ mRNA in a representative FAP 1 nerve with an antisense riboprobe (left panel) and a control sense riboprobe (middle panel). The far right panel shows in situ hybridization with the antisense IL-1 $\beta$ riboprobe and a control nerve (right panel).
A

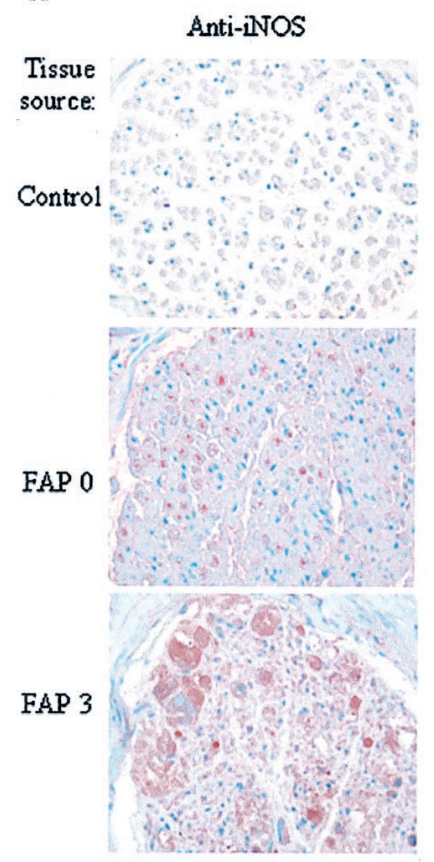

C

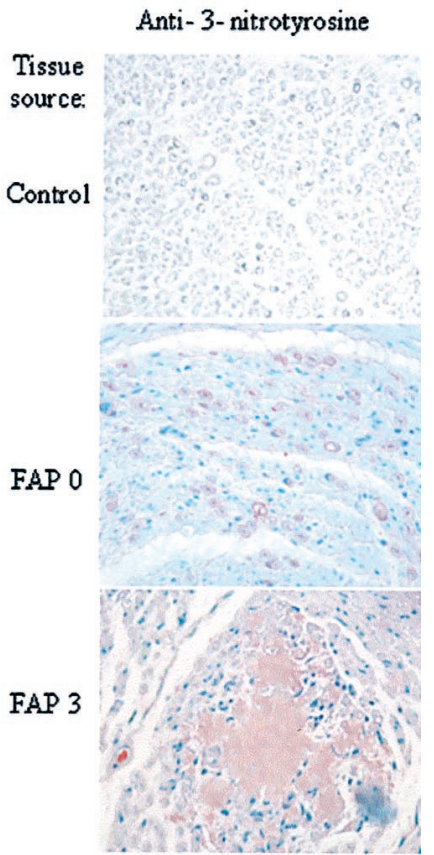

B

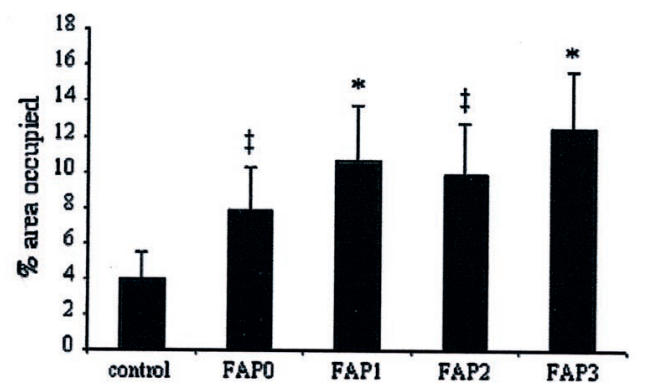

Figure 3. Oxidative stress in FAP. $A$, iNOS immunohistochemistry of representative nerves from a normal individual (left panel), FAP 0 (middle panel), and FAP 3 patients (right panel); 40× magnification. $B$, Quantitation of immunohistochemical images of iNOS staining in control individuals $(n=4)$ and FAP patients $(\mathrm{n}=16)$. Data are represented as percentage area occupied $\pm \mathrm{SD}\left({ }^{*} p<0.01,{ }^{*} p<0.02\right)$. $C$, 3-NT immunohistochemistry of representative nerves from normal individuals (left panel), an FAP 0 patient (middle panel), and an FAP 3 patient (right panel); $40 \times$ magnification.

pression of RAGE transcripts in each of these cell types (Fig. $5 A$ ). Cultures were incubated with TTR fibrils for $12 \mathrm{hr}$, and expression of TNF- $\alpha$ and IL- $1 \beta$ transcripts was studied by PCR. Induction of transcripts for each of these cytokines was observed in the different cell types by fibrillar, but not soluble, TTR (Fig. $5 B)$. Furthermore, antibody blocking experiments demonstrated that preincubation of cultures with anti-RAGE IgG prevented cytokine expression, whereas nonimmune IgG at the same concentration was without effect (Fig. $5 B$ ). In contrast to these results with RAGE-bearing cells, we also studied cultured MEF1. These cells did not display RAGE transcripts (Fig. 5A) and when exposed to TTR fibrils did not display induction of TNF- $\alpha$ or IL- $1 \beta$ transcripts (Fig. $5 B$ ).

In view of enhanced expression of iNOS in FAP biopsies, we used the same cell culture system to assess the effect of TTR 
A

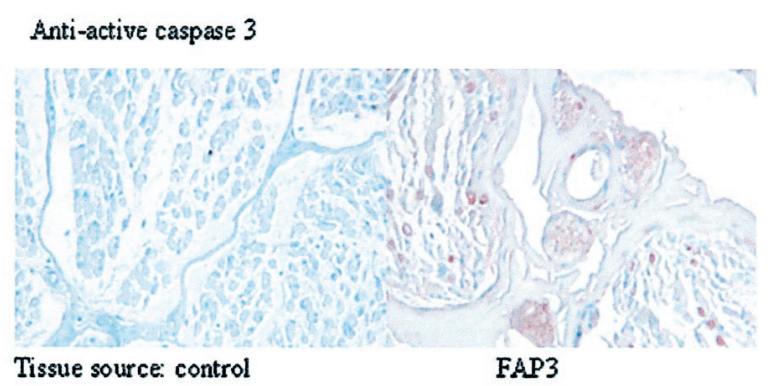

B

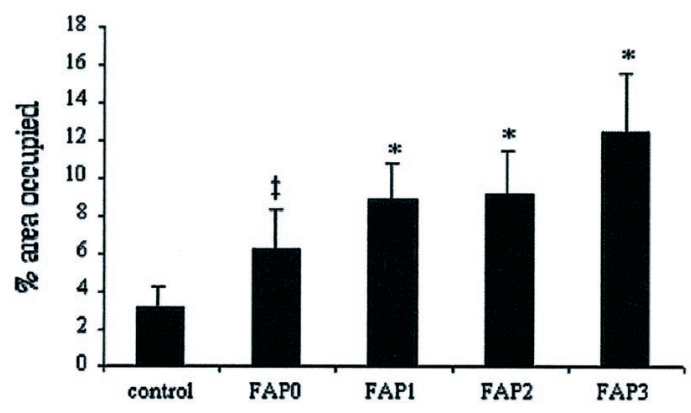

Figure 4. Apoptosis in FAP. A, Active caspase-3 immunohistochemical staining of a representative FAP 3 (right) and control nerve (left); 40× magnification. $B$, Quantitation of immunohistochemical images of active caspase-3 staining in control individuals $(n=4)$ and FAP patients $(n=$ 16). Data are represented as percentage area occupied $\pm \mathrm{SD}\left({ }^{*} p<0.003\right.$, $\ddagger p<0.03)$.

fibril-RAGE interaction on transcripts for iNOS. Using RN-22 cells, mouse Schwann cells, and PC-12 cells, TTR fibrils, but not soluble TTR, induced transcripts for iNOS (Fig. 5C). Expression of iNOS mRNA in mouse Schwann cells and PC-12 cells exposed to TTR fibrils was blocked by anti-RAGE IgG, but not by nonimmune $\operatorname{IgG}$ (Fig. 5C). These data are consistent with the capacity of RAGE engagement by TTR fibrils to activate signaling cascades in critical target cells for amyloid, resulting in expression of mediators observed in FAP nerve biopsies.

\section{Binding of TTR fibrils to RAGE induces cell death}

Complementary experiments were performed in cell cultures with $\mathrm{PC} 12$ and $\mathrm{RN}-22$ cells to determine whether sustained RAGE interaction with TTR fibrils ( $24 \mathrm{hr}$ ) might push cells into an apoptotic pathway. RN22 cells incubated with TTR fibrils (the latter preparations were composed of short fibrils and aggregates of TTR, determined on the basis of electron microscopy; data not shown) displayed increased caspase-3 activity in a dose- and time-dependent manner (Fig. 6A,B). Only fibrillar TTR was able to induce caspase-3 activity, whereas soluble TTR was without effect (Fig. 6C). Blockade of RAGE, using anti-RAGE IgG, demonstrated dose-dependent suppression of caspase-3 activity (by $\sim 60 \%$ ), whereas nonimmune $\operatorname{IgG}$ at the same concentration was without effect (Fig. 6C). Furthermore, addition of excess soluble RAGE, the extracellular portion of the receptor that binds ligand and prevents its interaction with cell surface RAGE, similarly prevented caspase-3 activation (Fig. 6C). PC-12 cells also displayed RAGE-dependent activation of caspase-3 after 24 $\mathrm{hr}$ of incubation with fibrillar TTR (Fig. 6D).

These results were consistent with the induction of programmed cell death in RN-22 and PC-12 cells exposed to RAGE ligands for $24 \mathrm{hr}$. To ascertain whether the cell death pathway had

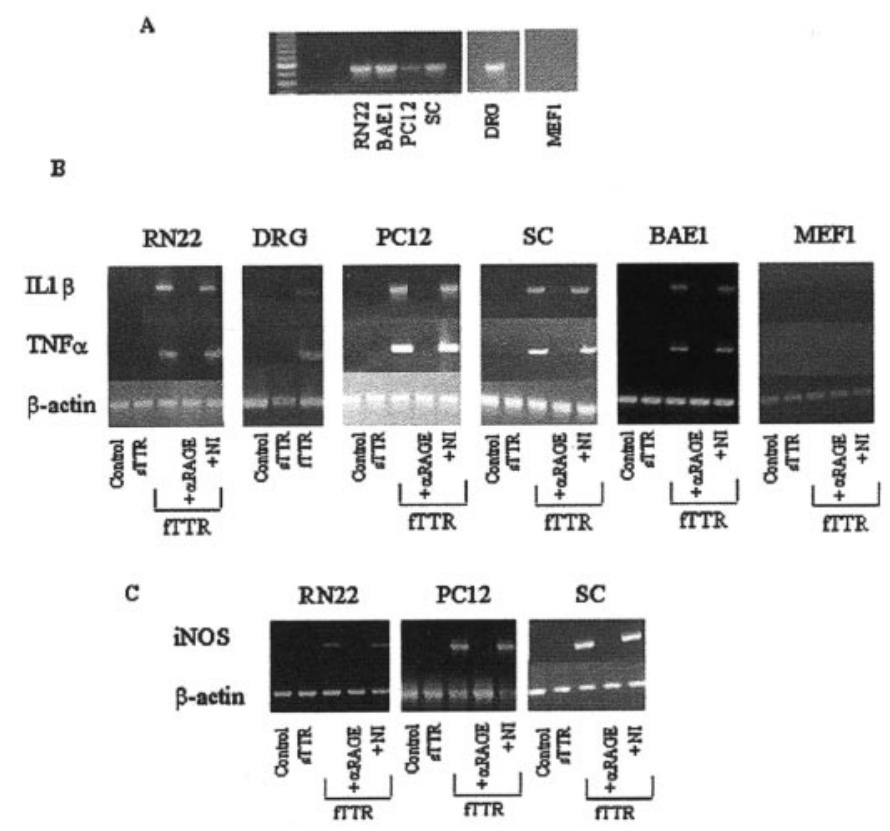

Figure 5. RAGE-dependent activation of proinflammatory cytokines and iNOS by TTR fibrils. $A$, RT-PCR analysis of RN22, BAE1, PC12, primary SC, neuron-DRG, and MEF1 cells with primers for RAGE. $B$, RT-PCR analysis of RN22, neuron-DRG, primary SC, PC12, BAE1, and MEF1 cells with primers for TNF- $\alpha$, IL- $1 \beta$, and $\beta$-actin. Cells were exposed for $6 \mathrm{hr}$ to assay buffer (Control), $0.5 \mu \mathrm{M}$ soluble TTR (sTTR), or $0.5 \mu \mathrm{M}$ TTR fibrils $(f T T R)$. Where indicated, cells were preincubated with $10 \mu \mathrm{g} / \mathrm{ml}$ of polyclonal anti-R AGE $(\alpha R A G E)$ or nonimmune IgG $(N I)$, and then exposed to fTTR $(0.5 \mu \mathrm{M})$. $C$, RT-PCR analysis of RN22, PC12 cells, and mouse primary SC with primers for iNOS and $\beta$-actin. Cells were exposed for $12 \mathrm{hr}$ to assay buffer (Control), $0.5 \mu \mathrm{M}$ soluble TTR $(s T T R)$, or $0.5 \mu \mathrm{M}$ TTR fibrils $(f T T R)$. Where indicated, cells were preincubated with $10 \mu \mathrm{g} / \mathrm{ml}$ of polyclonal anti-RAGE $(\alpha R A G E)$ or nonimmune $\operatorname{IgG}(N I)$ and then exposed to fTTR $(0.5 \mu \mathrm{M})$.

actually been triggered, DNA fragmentation was evaluated. Incubation of fibrillar TTR, but not soluble material at the same concentration, with RN-22 and PC-12 cells caused an increase in DNA fragmentation in each of the cell types (Fig. $6 E, F$ ). In each case, addition of anti-RAGE IgG blocked DNA fragmentation caused by fibrillar TTR by $\sim 70 \%$ (Fig. $6 E, F$ ).

\section{Schwann cell expression of neurotrophins in response to TTR: in vitro and in vivo studies}

Neurotrophins, namely BDNF, NGF, and NT-3, have an important role in the survival and regeneration of neuronal populations (Frostick et al., 1998). After nerve injury, both NGF and BDNF mRNAs, normally present at low levels in the nerve, increase in SCs (Frostick et al., 1998). In contrast, NT-3 expression is generally downregulated after nerve injury. In the case of FAP, no studies addressing trophic support of neurons have been reported. To assess the effect of TTR fibrils on neurotrophins, RN22 cells were incubated with TTR for $12 \mathrm{hr}$, and mRNA for NGF and NT-3 was monitored by RT-PCR. Fibrillar TTR, but not soluble TTR, induced transcripts for both NGF and NT-3 (Fig. 7A). In contrast, BDNF expression remained at low levels despite the presence of fibrillar TTR (Fig. 7A). However, when we assessed the expression of these neurotrophins in FAP nerve biopsies by immunohistochemistry, there were no changes in their expression in FAP nerves, compared with samples from control subjects (Fig. $7 B, C)$. In fact, the expression of NGF actually decreased in FAP3 patients $(p<0.002)$, and this decrease seemed most prominent in 
A
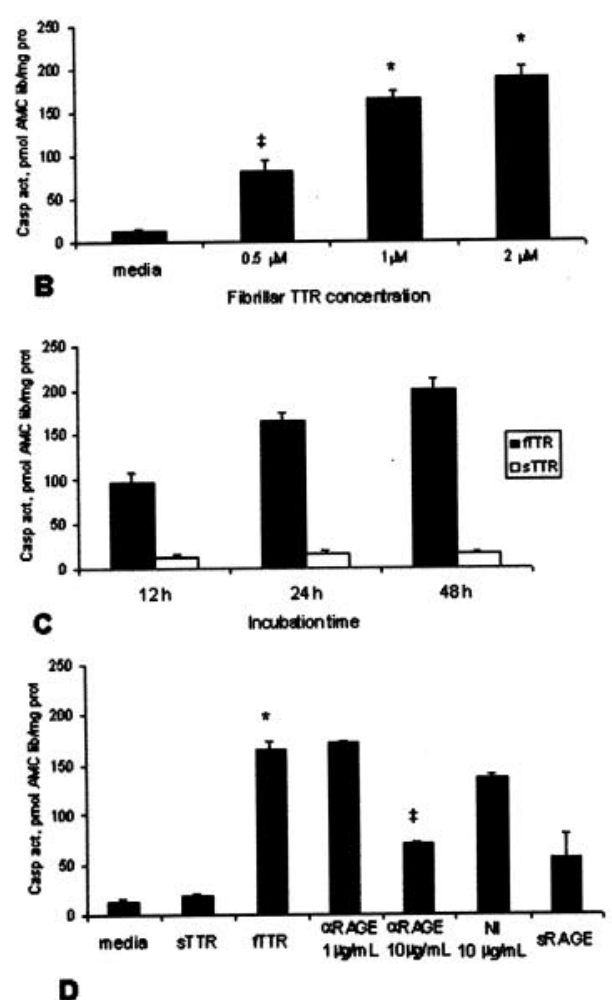

D
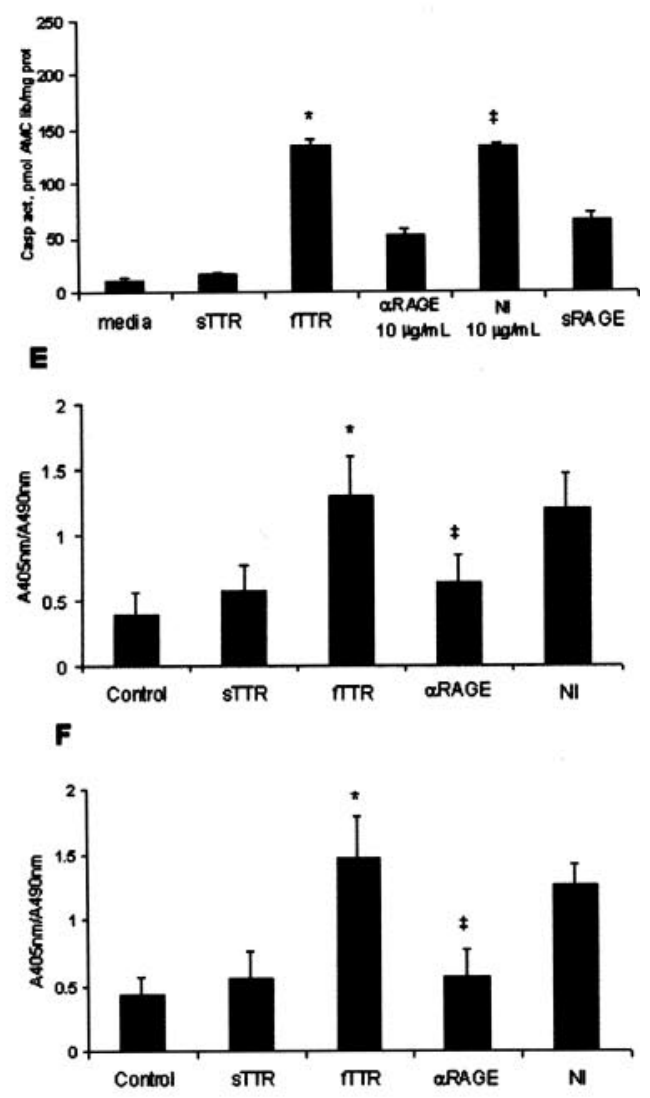

Figure 6. A, Dose-dependent induction of caspase-3 activity in RN22 cells exposed for $24 \mathrm{hr}$ to the indicated amounts of TTR fibrils ${ }^{*} p<$ $\left.0.001,{ }^{\ddagger} p<0.004\right)$. $B$, Time-dependent induction of caspase-3 activity in RN22 cells exposed for the indicated times to $1 \mu \mathrm{M}$ TTR fibrils. proximity to sites of massive TTR deposition (Fig. 7B). These data suggest an apparent lack of responsiveness of the SC in vivo in the setting of FAP to produce neurotrophins in a context of apparent neuronal stress. In contrast, cultured SCs exposed to neurotrophins did display increased expression of NGF and NT-3.

\section{DISCUSSION}

Although not as common as other forms of amyloidoses, such as Alzheimer's disease, FAP is a devastating neurodegenerative disorder for certain populations, such as those in northeast Portugal. Traditionally, it has been postulated that amyloid physically displaces normal elements of peripheral nerves, ultimately resulting in neuronal loss. Our data indicate that evidence of neuronal stress in patients with FAP begins at a very early stage; increased expression of RAGE, proinflammatory cytokines, and iNOS in peripheral nerve axons was observed before amyloid deposits were detected based on Congo red staining (FAP 0). This leads to the following question: what starts off the cascade of cellular perturbation, especially if the amyloid deposits do not seem to be the primary cause? Because mutant TTR must be at the root of the problem, we propose that "pathogenic" forms of TTR derived from the amyloidogenic variants, but not sufficiently abundant to appear as Congophilic deposits, are likely to be involved. In view of previous data demonstrating that normal TTR binds RAGE only when not complexed with its physiologic ligand retinol binding protein and that preformed fibrils of TTR (whether derived from mutant or wild-type transthyretin) similarly interact with the receptor (Sousa et al., 2000), it is possible that deposition of TTR in the form of small aggregates free of retinol binding protein occurs locally before overt amyloid deposition. This scenario would be consistent with the emerging role for pathogenic forms of amyloid- $\beta$ peptide in cellular perturbation underlying Alzheimer's disease (Eisenhauer et al., 2000). Experiments in transgenic mice expressing mutant forms of amyloid- $\beta$ precursor protein associated with familial Alzheimer's disease have shown the development of electrophysiologic and other changes in cellular function before or even without the presence of parenchymal plaques (Hsiao et al., 1995; Hsia et al., 1999). Consistent with this concept, toxic effects of soluble, relatively small $\mathrm{A} \beta$ assemblies have been observed (Roher et al., 1996). However, the precise nature of the pathogenic $\mathrm{A} \beta$ species is far from clear, ranging from mature fibrils to much smaller assemblies (Hensley et al., 1994; Snyder et al., 1994; Lorenzo and Yankner, 1996; Walsh et al., 1999).

\section{$\leftarrow$}

$C$, Activation of caspase-3 in RN22 cells exposed for $24 \mathrm{hr}$ to either $1 \mu \mathrm{M}$ soluble TTR ( $s T T R)$ or $1 \mu \mathrm{M}$ TTR fibrils $(f T T R)$. Where indicated, cells were preincubated with polyclonal anti-RAGE $(\alpha R A G E)$, nonimmune $\operatorname{IgG}(N I)$, or $20 \times$ molar excess of soluble RAGE $(s R A G E)$. Then these cultures were exposed to fTTR $(1 \mu \mathrm{M})\left({ }^{*} p<0.001,{ }^{\ddagger} p<0.003\right)$. $D$, Activation of caspase-3 in PC12 cells exposed for $24 \mathrm{hr}$ to either $1 \mu \mathrm{M}$ soluble TTR (sTTR) or $1 \mu \mathrm{M}$ TTR fibrils (fTTR). Where indicated, cells were preincubated with polyclonal anti-RAGE $(\alpha R A G E)$, nonimmune $\operatorname{IgG}(N I)$, or $20 \times$ molar excess of soluble RAGE $(s R A G E)$. Then these cultures were exposed to fTTR $\left.(1 \mu \mathrm{M}){ }^{*} p<0.001,{ }^{\ddagger} p<0.003\right)$. $E$, DNA fragmentation in RN22 cells exposed for $24 \mathrm{hr}$ to assay buffer (Control), $2 \mu \mathrm{M}$ soluble TTR $(s T T R)$, or $2 \mu \mathrm{M}$ TTR fibrils $(f T T R)$. Some cells were preincubated with $10 \mu \mathrm{g} / \mathrm{ml}$ of polyclonal anti-RAGE $(\alpha R A G E)$ or nonimmune $\operatorname{IgG}(N I)\left({ }^{*} p<0.005,{ }^{*} p<0.02\right) . F$, DNA fragmentation in PC12 cells exposed for $24 \mathrm{hr}$ to assay buffer (Control), $2 \mu \mathrm{M}$ soluble TTR $(s T T R)$, or $2 \mu \mathrm{M}$ TTR fibrils $(f T T R)$. Where indicated, cells were preincubated with $10 \mu \mathrm{g} / \mathrm{ml}$ polyclonal anti-RAGE $(\alpha R A G E)$ or nonimmune $\operatorname{IgG}(N I)\left({ }^{*} p<0.004,{ }^{*} p<0.01\right)$. 
A

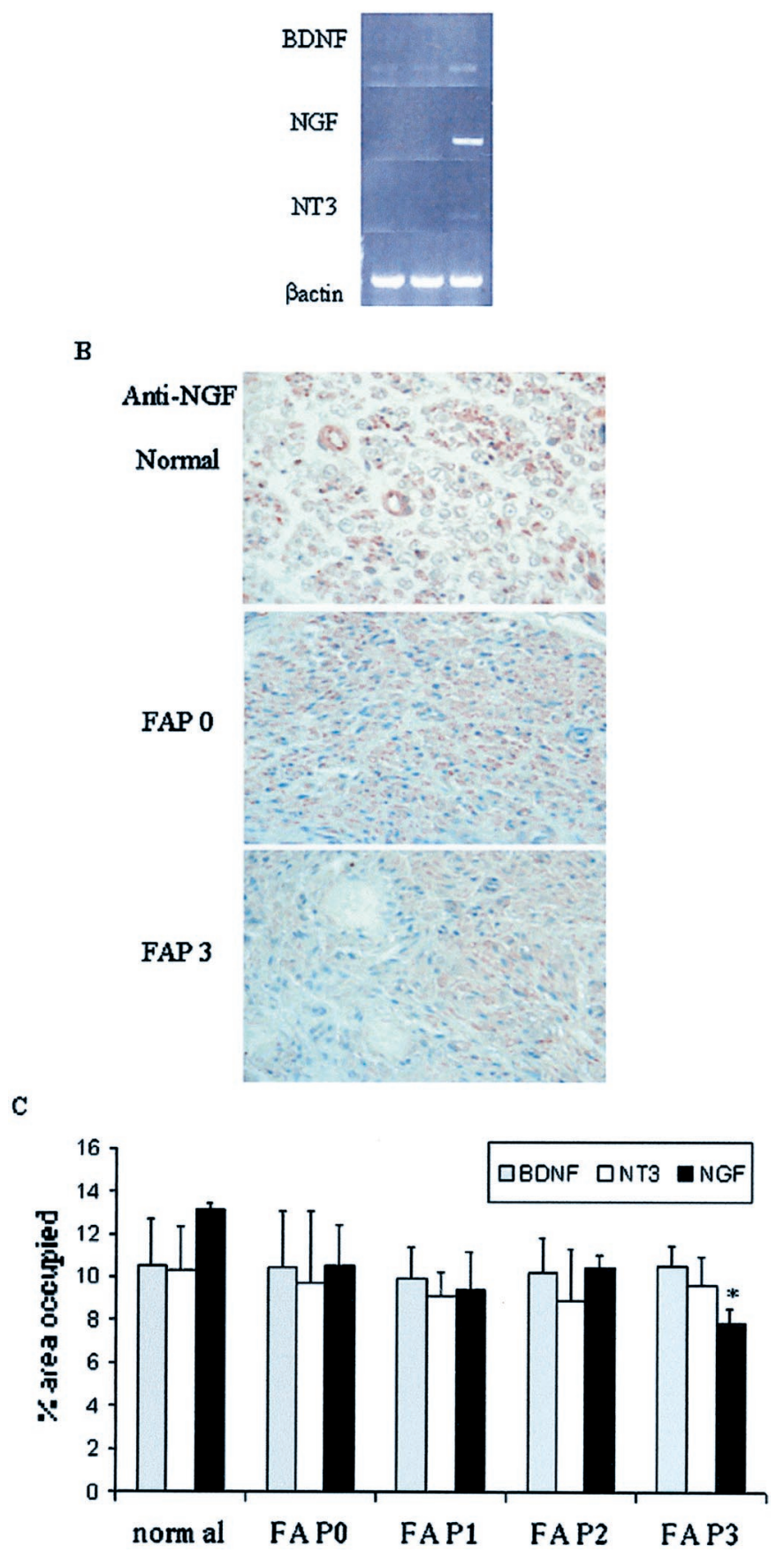

Figure 7. Neurotrophin expression in FAP. $A$, RT-PCR analysis using primers for BDNF, NGF, and NT3, of RN22. Cells were exposed for 12 hr to assay buffer (control), $1 \mu \mathrm{M}$ sTTR, or $1 \mu \mathrm{M}$ fTTR. $B$, NGF immunohistochemistry of representative nerves from normal individuals (top panel), FAP 0 patients (middle panel), and FAP 3 patients (bottom panel); 60× magnification. $C$, Quantitation of immunohistochemical images corresponding to NGF, BDNF, and NT-3 staining in control individuals $(n=3)$ and FAP patients $(n=16)$. Data are represented as percentage area occupied $\pm \mathrm{SD}\left({ }^{*} p<0.002\right)$.

Although further experiments will be required to understand the nature of the pathogenic form(s) of TTR relevant to the earliest stages of FAP, our data clearly demonstrate that RAGE is upregulated in peripheral neurons at early times and that this is magnified and persists throughout the course of the disease. In this context, it should be noted that the fibrillar material prepared in vitro for our cell culture experiments was composed of short fibrils and amorphous aggregates (by ultrastructural analysis). This is quite similar to the composition of TTR immunoreactive deposits from FAP 0 patients based on electron microscopy (M. Sousa, D. Stern, and M. Saraiva, unpublished observations). In view of the coinciding expression of RAGE and markers of cell stress in FAP nerves, it is tempting to speculate that these events may be related. Support for such an association must await the development of an appropriate animal model of TTR amyloid polyneuropathy. However, the results of our cell culture studies suggest that RAGE-induced cellular perturbation could prove relevant. Experiments in rat pheochromocytoma PC-12 cells demonstrated early induction of cytokines and iNOS. On the basis of previous results demonstrating that TTR fibrils cause activation of NF- $\kappa$ B in a RAGE-dependent manner (Sousa et al., 2000), it is possible that the latter underlies increased iNOS expression. Such observations also suggest that early in the disease, RAGE-induced cell stress might serve a protective role, because $\mathrm{NF}-\kappa \mathrm{B}$ promotes anti-apoptotic programs, including transcription of inhibitor of apoptosis protein genes (Chu et al., 1997). However, longer incubations of TTR fibrils with PC-12 cells pushed them into an apoptotic pathway, as evidenced by increased capase- 3 activity and DNA fragmentation. Thus, the ultimate consequence of sustained RAGE-TTR fibril interaction in the context of PC-12 cells is one of cell death. The latter might result from ligand-induced upregulation of RAGE (Schmidt et al., 2000) recruiting additional signaling pathways that ultimately overwhelm protective mechanisms. These observations suggest the relevance of RAGE-ligand interaction in the progression from cell stress to apoptosis, which fits the protracted course of neurodegenerative disorders.

One of the most striking features of our in vivo data concerns the lack of changes in Schwann cells in FAP biopsies (in terms of expression of RAGE, cytokines, iNOS, and neurotrophins), although previous studies would suggest that they are intimately associated with amyloid deposits (Coimbra and Andrade, 1971a,b). In fact, our initial hypothesis was that RAGE-bearing Schwann cells might provide a source of mediators ultimately impacting negatively on the function of peripheral neurons. However, upregulation of RAGE, TNF- $\alpha$, IL- $1 \beta$, and iNOS in FAP biopsies was particularly evident in neurons, not in Schwann cells. In contrast, our studies with cultured Schwann cells, both a cell line and primary cultures derived from dorsal root ganglia, demonstrated expression of RAGE and the capacity to evolve the same response mechanisms as $\mathrm{PC}-12$ cells, with respect to expression of mediators after exposure to TTR fibrils. At present, it is unclear why Schwann cells did not display upregulation of RAGE, cytokines, or iNOS in FAP nerve biopsies. These results led us to consider the alternative hypothesis that Schwann cells in FAP might impact on neuronal properties via an indirect mechanism, namely diminished expression of neurotrophic factors. Consistent with this concept, our studies evaluating the expression of BDNF, NGF, and NT-3 did not show increased expression in FAP nerve biopsies, in either SC or other cellular elements. The consequent lack of trophic factors might be relevant for neuronal dysfunction and, ultimately, cell death in FAP. The reason for the apparent lack of SC responsiveness, with respect to the host response to TTR amyloid in FAP, is not clear and requires further analysis. 
Another striking feature of FAP nerve biopsies was the lack of an immune/inflammatory infiltrate despite the production of IL $-1 \beta$ and TNF- $\alpha$ by axons. Although it might be argued that the cytokines are not effectively released into the nerve bed (because staining was largely restricted to axons), it is more likely that free polypeptides diff used away from the axon and were not adequately visualized by immunostaining. Furthermore, we would predict that other mechanisms must be operative to prevent recruitment of immune/inflammatory effector cells. This pathologic picture is certainly different from what is observed in the CNS. Neuritic plaques in Alzheimer's disease are well known for their association with activated microglia and astrocytes, which might contribute to protective or pathogenic mechanisms (Akiyama et al., 2000). In this context, it is possible that if a humoral immune response selective for pathogenic TTR species could be elicited in humans (by analogy with $\mathrm{A} \beta$ immunization studies in mice) (Schenk et al., 1999; Janus et al., 2000; Morgan et al., 2000), resulting in attraction of mononuclear phagocytes to sites of amyloid deposition, these cells might accelerate amyloid clearance. Considering the apparent absence of mononuclear phagocytes in FAP lesions, the results of an influx of such cells for removing amyloid could be considerable, although the ultimate outcome for neuronal function might be complex (especially if products of inflammatory cells perturbed neuronal function).

The results of our experiments provide support for a possible link between RAGE and neuronal dysfunction underlying FAP. Although future studies will be required to establish whether this link reflects a cause-effect relationship, our studies have already provided insights into selective neuronal perturbation in FAP biopsies occurring before overt amyloid deposition.

\section{REFERENCES}

Akiyama H, Arai T, Kondo H, Tanno E, Haga C, Ikeda K (2000) Cell mediators of inflammation in the Alzheimer disease brain. Alzheimer Dis Assoc Disord 14[Suppl]1:S47-53.

Almeida MR, Damas AM, Lans MC, Brower A, Saraiva MJ (1997) Thyroxine binding to transthyretin Met 119. Comparative studies of different heterozygotic carriers and structural analysis. Endocrine 6:309-315.

Bonifacio MJ, Sakaki Y, Saraiva MJ (1996) "In vitro" amyloid fibril formation from transthyretin: the influence of ions and the amyloidogenicity of TTR variants. Biochim Biophys Acta 1316:35-42.

Brett J, Schmidt AM, Yan SD, Zou YS, Weidman E, Pinsky D, Nowygrod R, Neeper M, Przysiecki C, Shaw A, Stern D (1993) Survey of the distribution of a newly characterized receptor for advanced glycation end products in tissues. Am J Pathol 143:1699-1712.

Calabrese V, Bates TE, Stella AMG (2000) NO synthase and NOdependent signal pathways in brain aging and neurodegenerative disorders: the role of oxidant/antioxidant balance. Neurochem Res 25:1315-1341.

Chu ZL, McKinsey TA, Liu L, Gentry JJ, Malim MH, Ballard DW (1997) Suppression of tumor necrosis factor-induced cell death by inhibitor of apoptosis c-IAP2 is under NF-kappaB control. Proc Natl Acad Sci USA 94:10057-10062.

Coimbra A, Andrade C (1971a) Familial amyloid polyneuropathy: an electron microscope study of peripheral nerve in five cases. I. Interstitial changes. Brain 94:199-206.

Coimbra A, Andrade C (1971b) Familial amyloid polyneuropathy: an electron microscope study of peripheral nerve in five cases. II. Nerve fibril changes. Brain 94:207-212.

Combs CK, Karlo JC, Kao SC, Landreth GE (2001) $\beta$-Amyloid stimulation of microglia and monocytes results in TNF- $\alpha$-dependent expression of inducible nitric oxide synthase and neuronal apoptosis. J Neurosci 21:1179-1188.

Eisenhauer PB, Johnson RJ, Wells JM, Davies TA, Fine REJ (2000) Toxicity of various amyloid beta peptide species in cultured human blood-brain barrier endothelial cells: increased toxicity of Dutch type mutant. Neurosci Res 60:804-810.

Frostick SP, Yin Q, Kemp GJ (1998) Schwann cells, neurotrophic factors, and peripheral nerve regeneration. Microsurgery 18:397-405.

Fujimura H, Lacroix C, Said G (1991) Vulnerability of nerve fibres to ischaemia. A quantitative light and electron microscope study. Brain 114:1929-1942.

Hengartner MO (2000) The biochemistry of apoptosis. Nature 407:685-687.

Hensley K, Carney JM, Mattson MP, Aksenova M, Harris M, Wu JF, Floyd RA, Butterfield DA (1994) A model for beta-amyloid aggregation and neurotoxicity based on free radical generation by the peptide: relevance to Alzheimer disease. Proc Natl Acad Sci USA 91:3270-3274.

Hofmann MA, Drury S, Fu C, Qu W, Taguchi A, Lu Y, Avila C, Kambham N, Bierhaus A, Nawroth P, Neurath MF, Slattery T, Beach D, McClary J, Nagashima M, Morser J, Stern D, Schmidt AM (1999) RAGE mediates a novel proinflammatory axis: a central cell surface receptor for S100/calgranulin polypeptides. Cell 97:889-901.

Hofmann MA, Lalla E, Lu Y, Gleason MR, Wolf BM, Tanji N, Ferran Jr LJ, Kohl B, Rao V, Kisiel W, Stern DM, Schmidt AM (2001) Hyperhomocysteinemia enhances vascular inflammation and accelerates atherosclerosis in a murine model. J Clin Invest 107:675-683.

Hori O, Brett J, Slattery T, Cao R, Zhang J, Chen JX, Nagashima M, Lundh ER, Vijay S, Nitecki D, Stern D, Schmidt AM (1995) The receptor for advanced glycation end products (RAGE) is a cellular binding site for amphoterin. Mediation of neurite outgrowth and coexpression of rage and amphoterin in the developing nervous system. J Biol Chem 270:25752-25761.

Hsia AY, Masliah E, McConlogue L, Yu GQ, Tatsuno G, Hu K, Kholodenko D, Malenka RC, Nicoll RA, Mucke L (1999) Plaqueindependent disruption of neural circuits in Alzheimer's disease mouse models. Proc Natl Acad Sci USA 96:3228-3233.

Hsiao KK, Borchelt DR, Olson K, Johannsdottir R, Kitt C, Yunis W, Xu S, Eckman C, Younkin S, Price D (1995) Age-related CNS disorder and early death in transgenic FVB/N mice overexpressing Alzheimer amyloid precursor proteins. Neuron 15:1203-1218.

Janus C, Pearson J, McLaurin J, Mathews PM, Jiang Y, Schmidt SD, Chishti MA, Horne P, Heslin D, French J, Mount HT, Nixon RA, Mercken M, Bergeron C, Fraser PE, St. George-Hyslop P, Westaway D (2000) A beta peptide immunization reduces behavioural impairment and plaques in a model of Alzheimer's disease. Nature 408:979-982.

Lorenzo A, Yankner BA (1996) Amyloid fibril toxicity in Alzheimer's disease and diabetes. Ann NY Acad Sci 777:89-95.

Morgan D, Diamond DM, Gottschall PE, Ugen KE, Dickey C, Hardy J, Duff K, Jantzen P, DiCarlo G, Wilcock D, Connor K, Hatcher J, Hope C, Gordon M, Arendash GW (2000) A beta peptide vaccination prevents memory loss in an animal model of Alzheimer's disease. Nature 408:915-916.

Mrak RE, Sheng JG, Griffin WS (1995) Glial cytokines in Alzheimer's disease: review and pathogenic implications. Hum Pathol 26:816-823.

Radi R, Peluffo G, Alvarez MN, Naviliat M, Cayota A (2001) Unraveling peroxynitrite formation in biological systems. Free Radic Biol Med 30:463-488

Roher AE, Chaney MO, Kuo YM, Webster SD, Stine WB, Haverkamp LJ, Woods AS, Cotter RJ, Tuohy JM, Krafft GA, Bonnell BS, Emmerling MR (1996) Morphology and toxicity of Abeta-(1-42) dimer derived from neuritic and vascular amyloid deposits of Alzheimer's disease. J Biol Chem 271:20631-20635.

Said G, Ropert A, Faux N (1984) Length-dependent degeneration of fibers in Portuguese amyloid polyneuropathy: a clinicopathologic study. Neurology 34:1025-1032.

Saraiva MJ (2001) Transthyretin mutations in hyperthyroxinemia and amyloid diseases. Hum Mutat 17:493-503.

Saraiva MJ, Birken S, Costa PP, Goodman DS (1983) Amyloid fibril protein in familial amyloidotic polyneuropathy, Portuguese type. Definition of molecular abnormality in transthyretin (prealbumin). J Clin Invest 74:104-119.

Saraiva MJ, Costa PP, Goodman DS (1985) Biochemical marker in familial amyloidotic polyneuropathy, Portuguese type. Family studies on the transthyretin (prealbumin)-methionine-30 variant. J Clin Invest 76:2171-2177.

Schenk D, Barbour R, Dunn W, Gordon G, Grajeda H, Guido T, Hu K Huang J, Wood K, Khan K, Kholodenko D, Lee M, Liao Z, Lieberburg I, Motter R, Mutter L, Soriano F, Shopp G, Vasquez N, Vandevert C, Walker S, Wogulis M, Yednock T, Games D, Seubert P (1999) Immunization with amyloid-beta attenuates Alzheimer-disease-like pathology in the PDAPP mouse. Nature 400:116-117.

Schmidt AM, Yan SD, Wautier JL, Stern D (1999) Activation of receptor for advanced glycation end products: a mechanism for chronic vascular dysfunction in diabetic vasculopathy and atherosclerosis. Circ Res 84:489-497.

Schmidt AM, Yan SD, Yan SF, Stern DM (2000) The biology of the receptor for advanced glycation end products and its ligands. Biochim Biophys Acta 1498:99-111.

Smith MA, Richey Harris PL, Sayre LM, Beckman JS, Perry G (1997) Widespread peroxynitrite-mediated damage in Alzheimer's disease. J Neurosci 17:2653-2657.

Snyder SW, Ladror US, Wade WS, Wang GT, Barrett LW, Matayoshi ED, Huffaker HJ, Krafft GA, Holzman TF (1994) Amyloid-beta ag- 
gregation: selective inhibition of aggregation in mixtures of amyloid with different chain lengths. Biophys J 67:1216-1228.

Sousa MM, Yan SD, Stern D, Saraiva MJ (2000) Interaction of the receptor for advanced glycation end products (RAGE) with transthyretin triggers nuclear transcription factor $\mathrm{kB}(\mathrm{NF}-\kappa \mathrm{B})$ activation. Lab Invest 80:1101-1110.

Veerhuis R, Janssen I, De Groot CJ, Van Muiswinkel FL, Hack CE, Eikelenboom P (1999) Cytokines associated with amyloid plaques in Alzheimer's disease brain stimulate human glial and neuronal cell cultures to secrete early complement proteins, but not $\mathrm{C} 1$-inhibitor. Exp Neurol 160:289-299.

Walsh DM, Hartley DM, Kusumoto Y, Fezoui Y, Condron MM, Lomakin A, Benedek GB, Selkoe DJ, Teplow DB (1999) Amyloid beta- protein fibrillogenesis. Structure and biological activity of protofibrillar intermediates. J Biol Chem 274:25945-25952.

Yan SD, Chen X, Fu J, Chen M, Zhu H, Roher A, Slattery T, Zhao L, Nagashima M, Morser J, Migheli A, Nawroth P, Stern D, Schmidt AM (1996) RAGE and amyloid-beta peptide neurotoxicity in Alzheimer's disease. Nature 382:685-691.

Yan SD, Roher A, Schmidt AM, Stern DM (1999) Cellular cofactors for amyloid beta-peptide-induced cell stress. Moving from cell culture to in vivo. Am J Pathol 155:1403-1411.

Yan SD, Zhu H, Zhu A, Golabek A, Du H, Roher A, Yu J, Soto C, Schmidt AM, Stern D, Kindy M (2000) Receptor-dependent cel stress and amyloid accumulation in systemic amyloidosis. Nat Med 6:643-651. 